\title{
Mode of Feeding in Infancy and its Related Parameters
}

\author{
Rafia Bano*
}

Department of Clinical Nutrition, College of Applied Medical Sciences, University of Hail, KSA

\begin{abstract}
The study aims to assess the relation between breastfeeding duration and age at menarche. Analysis was based on a cross sectional study on adolescent girls in the age group $10-15$ years. The main outcome was selfreported age at menarche. Pearson's correlation was used to investigate the relation between duration of exclusive and any breastfeeding with age at menarche with adjustment sequentially for specific sets of known socioeconomic, maternal, and genetic, confounders [1].

Menarche is a critical biomarker in the reproductive life of females [2]. It serves as an intermediate health outcome that affects women's wellbeing at later stages of life [3]. There appears to be trend for decreasing age at menarche worldwide. There are contradictory reports of lowering age at menarche due to increasing BMI in the population [4]. The tempto, level of growth and maturation during adolescence may have important implication to future adult health. The purpose of the study was to examine mode of feeding in infancy and its effect on BMI and age at menarche [5].

700 girls, 10-15 years were selected by multistage random sampling procedure. Age of the girls, Socioeconomic Status, $\mathrm{BMI}$, menstrual status and mode of feeding in infancy were identified by questionnaire. Quetelet Index (wt/ $\left.\mathrm{h}^{2}\right) \mathrm{was}$ used to identify the BMI. B. G. Prasad method of social classification was used to grade the Socio economic Status [6].

Mean age at menarche was found to be $12.36 \pm 1.15$ years. It was observed that mode of feeding infancy was significantly correlated $(\mathrm{P}<0.01)$ with the age at menarche, Socioeconomic Status and educational qualification of mothers. However, the study suggested that girls who were formula fed deposit more body fat and were overweight.
\end{abstract}

Keywords: Mode of feeding, Body Mass Index, Menarche, Infancy.

\section{INTRODUCTION}

Menarche is however only a single event in the combination of physical changes which constitute puberty. There appears to be a trend of decreasing age at menarche worldwide [7]. Other factors aside, it is often assumed that this trend is due to increase in body fat mass secondary to excessive calorie consumption. There has been an increased incidence of obesity in the Indian subcontinent [8] and the question whether an earlier menarche is attributed to weight gain, is therefore an important one. Also the girls who were formula fed deposit more body fat than girls who were breast fed resulting in early attainment of menarche [7].

Early menarche is among the few established risk factors for breast cancer [9-11]. It has also been associated with metabolic syndrome [12], teenage depression [13], and overweight [14, 15].

Only recently have studies begun to investigate the effect of early life events on the timing of puberty, with the majority of studies focusing on birth weight, birth length, gestational age, and ponderal index $[1,3,16]$. Although nutrition in early development and childhood has a significant effect on the timing of menarche [17], it is surprising that little attention has been given to the

*Address correspondence to this author at the Department of Clinical Nutrition, College of Applied Medical Sciences, University of Hail, KSA;

Tel: 00966536662964; E-mail: rafiazafar78@gmail.com potential role of breastfeeding. Breastfeeding has been shown to be inversely associated with weight gain during childhood [18-20], which in itself is a risk factor for early age at menarche $[3,21]$.

Nutrition as an important regulator of the tempo of growth and obesity is usually associated with tall, childhood stature and earlier pubertal development [22]. According to Dunger et al., 2006 [22] mode of feeding in infancy is positively correlated to BMI with bottle fed girls having higher BMls. Several longitudinal studies have documented that timing of puberty is most closely linked to infant weight gain suggesting an early window for interventions of growth and adolescent development.

According to Ong KK (2009) [19], formula feeding results in faster early infancy weight gain and was associated with increased body fat mass at 10 years and also with earlier age at menarche. Schneider A P (1987) [23] showed in their study that improved nutrition during early childhood results in earlier attainment of fertility milestones.

According to Ginna Wall MN (2007) [24] breast feeding lowers the risk of obesity and decreases the ovulatory age.

\section{METHODOLOGY}

The present cross section study was under taken in adolescent school girls aged 10-15 years from four 
different regions of Aligarh city. A $2.7 \%$ sample from among the total adolescent school going girls during the academic session 2005-2006 was selected for the study.

The study was carried out using a pretested and modified questionnaire. Identification data and age of the girls were ascertained from school records. The girls were told to ask the questions regarding their mode of feeding in infancy, duration of breastfeeding and whether it was partial or exclusive from their mothers and was noted in the questionnaire in the follow up visits. Standing height was measured using stadiometre and weight was measured using standard weighing machine. These values were used to calculate BMI using quetelet index $\left(w t / h^{2}\right)$.

\section{Age at Menarche}

The analysis sample for the present study includes all girls who participated in the survey and had complete data on breastfeeding. The main outcome of the study was age at menarche, self reported in the surveys as the year of the occurrence of the first menstrual cycle. For the purpose of this study, age at menarche was used as a continuous and as a categorical variable. The categorical variable was grouped into early ( $<11.5$ years), average (11.5-13.5 years), and late ( $>13.5$ years) menarche. The age limit for early and late menarche was determined as 1 standard deviation away from the estimated mean age at menarche [3, 4]. Premenarcheal girls who were 14 years of age or older at the time of the interview were classified in the late menarche group [3, 6, 21].

\section{Breastfeeding}

The durations of exclusive breastfeeding and any breastfeeding were the main independent variables in the study.
Exclusive breastfeeding was defined as the intake of breast milk alone without any other type of milk, liquid, or food. Its duration was calculated as the infant's age when exclusive breastfeeding was terminated. Based on the recall of feeding patterns, this information was reported by the mother. Any breastfeeding, on the other hand, was defined as the intake of breast milk regardless of other type of food or drink intake. The duration of any breastfeeding, reported bimonthly by the mother for the first 24 months of life, was defined as the infant's age in days when any breastfeeding had been permanently stopped [28]. The present study has taken into account only the exclusively breast fed girls for statistical analysis.

ICMR classification was used to grade BMI [24]. B. G. Prasad method of social classification [6] modified as per the price index of 2002 was adopted for Socioeconomic Status. The selected sample was then categorized as High Income Group (HIG), Middle Income Group (MIG) and Low Income Group (LIG). Chi square and pearson's correlation was used to determine the association between age at menarche and other variables through SPSS-17.0 software.

\section{RESULTS}

Results of the study concluded that among 700 girls studied 400 were found to be post menarcheal. The mean age at menarche in the present study was found to be $12.36 \pm 1.15$ years (Table 2 ).

Table 1 shows that the correlation of mode of feeding in infancy was found to be significantly correlated $(P<0.05)$ with age of post menarcheal and inversely correlated with the age of non menarcheal girls $(P<0.05)$. It is noted from the table that the youngest menarcheal girls (age 10) were only bottle

Table 1: Relationship of Mode of Feeding in Infancy and Age According to Menarcheal Status

\begin{tabular}{|c|c|c|c|c|c|c|c|c|c|c|c|c|}
\hline \multirow{2}{*}{$\begin{array}{l}\text { Age } \\
\text { (yrs) }\end{array}$} & \multicolumn{6}{|c|}{ Menarcheal } & \multicolumn{6}{|c|}{ Non-menarcheal } \\
\hline & $\begin{array}{c}\text { Bottle } \\
\text { Fed }\end{array}$ & $\%$ & $\begin{array}{c}\text { Breast fed } \\
\text { (total) }\end{array}$ & $\%$ & Total & $\%$ & $\begin{array}{c}\text { Bottle } \\
\text { fed }\end{array}$ & $\%$ & $\begin{array}{c}\text { Breast fed } \\
\quad \text { (total) }\end{array}$ & $\%$ & Total & $\%$ \\
\hline 10 & 8 & 2.0 & - & - & 8 & 2.0 & 65 & 21.7 & 43 & 14.3 & 108 & 36.0 \\
\hline 11 & 22 & 5.5 & 11 & 2.8 & 33 & 8.3 & 39 & 13.0 & 44 & 14.7 & 83 & 27.7 \\
\hline 12 & 43 & 10.8 & 15 & 3.8 & 58 & 14.5 & 31 & 10.3 & 28 & 9.3 & 59 & 19.7 \\
\hline 13 & 59 & 14.8 & 30 & 7.5 & 89 & 22.3 & 10 & 3.3 & 19 & 6.3 & 29 & 9.7 \\
\hline 14 & 66 & 16.5 & 33 & 8.3 & 99 & 24.8 & 6 & 2.0 & 15 & 5.0 & 21 & 7.0 \\
\hline 15 & 61 & 15.3 & 52 & 13.0 & 113 & 28.3 & - & - & - & - & - & - \\
\hline \multirow[t]{2}{*}{ Total } & 259 & 64.8 & 141 & 35.3 & 400 & 100 & 151 & 50.3 & 149 & 49.7 & 300 & 100 \\
\hline & \multicolumn{6}{|c|}{$x^{2}=12.64 d f 5 ; P<0.05$} & \multicolumn{6}{|c|}{$x^{2}=11.6$ df $4 ; P<0.05$} \\
\hline
\end{tabular}


Table 2: Correlation Between Age at Menarche and Mode of Feeding in Infancy

\begin{tabular}{|c|c|c|c|c|}
\hline \multirow{2}{*}{ Age at menarche (years) } & \multirow{2}{*}{ Mean age at menarche } & \multicolumn{2}{|c|}{ Mode of feeding in infancy } & \multirow{2}{*}{ Total } \\
\cline { 3 - 5 } & & Bottle fed & Breast fed (Exclusive) & $103(28.8 \%)$ \\
\hline \hline $9.6-11.5$ & 10.81 & $75(18.8 \%)$ & $28(7.0 \%)$ & $235(58.0 \%)$ \\
\hline $11.6-13.5$ & 12.59 & $159(42.3 \%)$ & $66(16.5 \%)$ & $62(15.5 \%)$ \\
\hline $13.6-15$ & 14.08 & $259(64.8 \%)$ & $141(35.3 \%)$ & $400(100 \%)$ \\
\hline Total & 12.36 & & $11.8 \%)$ & $14 \%)$ \\
\hline
\end{tabular}

$x^{2}-52.90$ at df $2 ; p<0.01$

fed. Also the number of breast fed girls increased linearly with increasing age of menarcheal girls.

Table 2 shows the distribution of exclusively breast fed and bottle fed girls according to age at menarche. It is clear from the table that among the total population the percentage of bottle fed girls was found higher $(18.7 \%)$ in the early maturing age group $(9.6-11.5)$ than the late maturing population (3.7\%). Simultaneously, the number of totally breast fed girls was higher $(11.7 \%)$ among the late matures as compared to $7.0 \%$ early matures.

On analyzing percentages for each age group separately it is clear that the percentage of bottle fed girls show a steady decrease with increasing age at menarche from $72.8 \%$ to $71.9 \%$ followed by only $24.2 \%$. On the other hand the percentage of totally breast fed girls increased with increasing age at menarche from $27.1 \%$ girls (age group 9.6yr - 11.5yr) to $28.1 \%$ (age group $11.6 \mathrm{yr}-13.5 \mathrm{yr}$ ) up to $75.8 \%$ girls (age group $13.6 \mathrm{yr}-15 \mathrm{yr}$ ), showing a positive correlation $(\mathrm{P}<0.001)$ between exclusive breast feeding and age at menarche. On applying chi square- test, $\mathrm{P}$ value was found to be $<0.001$ which was highly significant $\left(x^{2}=52.9\right.$ at $\left.\mathrm{df} 2\right)$.

According to Table 3, results of the study show that mode of feeding in infancy was insignificantly correlated $(P>0.05)$ with Body Mass Index. Although it was noted from Table to that the number of overweight girls was more among bottle fed as compared to the exclusively breastfed girls. Also Among the total 5 overweight girl the majority (i.e. 4) were found to be bottle fed.

Table 4 revealed that the mode of feeding in infancy was significantly correlated with the socio economic status $(\mathrm{P}<0.05)$. The number and percentage of bottle fed girls increased from $130(31.7 \%)$ to $175(42.6 \%)$ in

Table 3: Correlation of BMI and Mode of Feeding Infancy

\begin{tabular}{|c|c|c|}
\hline \multirow{2}{*}{ BMI $\left(\mathbf{w t} / \mathbf{h t}^{2}\right)$} & \multicolumn{2}{|c|}{ Mode of feeding in infancy } \\
\cline { 2 - 3 } & Bottle fed & Breast fed (Exclusive) \\
\hline \hline Under weight & $240(58.5 \%)$ & $186(64.2 \%)$ \\
\hline Normal & $166(40.4 \%)$ & $103(35.5 \%)$ \\
\hline Over weight & $4(1 \%)$ & $1(0.4 \%)$ \\
\hline Total & $410(100 \%)$ & $290(100 \%)$ \\
\hline
\end{tabular}

Pearson's correlation $x^{2}-2.914$ at df $4 ; p>0.05$.

Table 4: Correlation of Income Group and Mode of Feeding in Infancy

\begin{tabular}{|c|c|c|c|}
\hline \multirow{2}{*}{ Income group } & \multicolumn{2}{|c|}{ Mode of feeding in infancy } & \multirow{2}{*}{ Total } \\
\cline { 2 - 4 } & Bottle fed & Exclusively Breast fed & 243 \\
\hline \hline LIG & $130(31.7 \%)$ & $113(39 \%)$ & 193 \\
\hline MIG & $105(25.6 \%)$ & $88(30.34 \%)$ & 264 \\
\hline HIG & $175(42.6 \%)$ & $89(30.7 \%)$ & 700 \\
\hline Total & $410(100 \%)$ & $290(100 \%)$ & 2 \\
\hline
\end{tabular}

Pearson's correlation $x^{2}-14.5$ at df $4 ; p<0.05$. 
Table 5: Correlation between Education of Mother and Mode of Feeding in Infancy

\begin{tabular}{|c|c|c|c|}
\hline \multirow{2}{*}{\begin{tabular}{|c|c|} 
Education of mother \\
\cline { 2 - 4 }
\end{tabular}} & Bottle fed & Exclusively Breast fed \\
\hline \hline Illiterate & 8 & 2 & 10 \\
\hline Literate & 21 & 74 & 152 \\
\hline SSC & 78 & 38 & 121 \\
\hline SSSC & 83 & 103 & 231 \\
\hline UG & 128 & 38 & 96 \\
\hline PG & 58 & 6 & 40 \\
\hline
\end{tabular}

$x^{2}-28.4$ at df $6 ; p<0.001$

accordance to the rising income level. On the other hand the number of exclusively breast fed girls decreased from $113(39 \%)$ to 89 (30.7\%) with rising income of group. Also the number of bottle fed girls was highest in the High Income Group (HIG; ie.42.6\%) and the number of exclusive or totally breastfed girls was highest in Low Income Group (LIG ie 39\%) showing a positive correlation between the two.

According to Table 5, educational qualification of mothers was also found to be significantly correlated $(p<0.001)$ with exclusive breast feeding. Study also showed that the high percentage of highly qualified mothers used bottle feeding. Literacy level of mothers was found to be higher as the study was not community based.

\section{DISCUSSION}

The present study aimed to explore the association of breastfeeding with menarcheal age.After adjustment for potential confounders of the association of breastfeeding with age at menarche, exclusive breastfeeding duration retained an independent and significant association with age at menarche. Results suggest that nutrition in early development and childhood plays an important role in determining the timing of menarche. Breastfeeding in early life may prevent or delay weight gain during childhood [18-20]. According to a study conducted on Danish cohort, longer durations of any breastfeeding decreased the weight gain during the first year of life [18]. Babies breastfed for less than 20 weeks gained $317.4 \mathrm{~g}$ more during the first year of life than those who breastfed for more than 40 weeks [18]. As explained by Ong et al. [19], the growth patterns for 3-month-breastfed infants were slower than those for formula-fed infants for the first 5 years of life. Rapid weight gain during infancy has also been shown to increase the risk of attaining earlier menarche $[3,21]$. Using the same data set as the present study, Adair [3] revealed that faster growth in weight and/or length at 6 months of age also predicted young menarcheal age.

The results of the present study are in accordance with some other studies. According to Schneider A. P. (1987) [23], " breast feeding should be added to the list of factors that decrease ovulatory age and thereby decrease the risk of ovarian cancers".

Although the mechanism explaining the link between infant weight gain and age at menarche is still unclear, it has been speculated that a rise in leptin among rapid weight gainers triggers the onset of puberty. Similarly, the increased concentration of insulin like growth factor I due to weight gain during infancy may also promote the initiation of puberty [22].

According to another study by Ginna Wall, M. N. (2007) [24], "breast feeding lowers the risk of obesity, which in turn affects the age at menarche". They showed prevalence of obesity as $10.7 \%$ in breast fed girls in comparison with $47 \%$ of bottle fed girls. However, there is lack of available literature to date showing the extent to which breast feeding or bottle feeding during infancy affects the age at menarche. Therefore the present study covers the aspects which still need much attention in developing countries like India.

\section{SUMMARY}

Mode of feeding in infancy was found to be significantly correlated $(\mathrm{P}<0.05)$ with age at menarche, whereas mode of feeding in infancy was affected by socio economic status and mother education level. The present study showed no significant correlation 
$(P>0.05)$ between $\mathrm{BMI}$ and mode of feeding in infancy contrary to the studies by Novotny R (2003) [5] and Ong KK, (2009) [19]; showing a positive correlation between formula feeding and Body Mass Index.

Although no study has previously investigated the association between breastfeeding and menarcheal age as its primary objective, 3 studies examined this association as part of determining the predictors of menarche [5, 26, 27]. One of these studies by Novotny et al. [5] revealed that formula-fed girls were $2.7(95 \%$ confidence interval: $1.12,6.38)$ times more likely to attain early menarche than breastfed babies. The other 2 studies, however, failed to detect significant associations between breastfeeding and menarcheal timing [26, 27]. Several notable limitations such as small sample size, study design, long-term recall, and inconsistency in breastfeeding definitions limit the generalizability of these findings.

Mode of feeding in infancy i.e. breast feeding versus bottle feeding, is an important as well as the least explored factor especially from a country like India as well as abroad, probably due to the population biasing. According to the studies done on factors associated with age at menarche it is concluded that mode of feeding in infancy affects the adolescent weight and age of attainment of puberty signs, but there are limited researches showing any direct relationship with age at menarche, thus this area needs further in depth research. Results of this study could help promote breast feeding among young mothers through nutritionists and health workers, which has a lifelong effect on child's health and thus would greatly help to develop a healthy nation.

\section{REFERENCES}

[1] Sloboda DM, Hart R, Doherty DA, et al. Age at menarche: influences of prenatal and postnatal growth. J Clin Endocrinol Metab 2007; 92(1): 46-50.

http://dx.doi.org/10.1210/jc.2006-1378

[2] Thomas F, Renaud F, Benefice E, et al. International variability of ages at menarche and menopause: patterns and main determinants. Hum Biol 2001; 73(2): 271-90. http://dx.doi.org/10.1353/hub.2001.0029

[3] Adair LS. Size at birth predicts age at menarche [electronic article]. Pediatrics 2001; 107(4): e59. http://dx.doi.org/10.1542/peds.107.4.e59

[4] Demerath EW, Jones LL, et al. Rapid infant weight gain and advanced skeletal malnutrition in childhood. J Pediatrics 2009; 155(3): 355-61, E, Pub, May 5, 2009.

[5] Novotny R, Daida YG, Grova JS, et al. Formula feeding in infancy is associated with adolescent body fat and earlier menarche. Cell Mod Biol 2003; 49(8): 128-93.

[6] Rao BT. Sociology in Medicine; $1^{\text {st }}$ ed. Shree Graphics Gumtur Publishers 2002.
[7] Ghai OP. Essential Pediatrics; Deptt. of Pediatrics, All India Institute of Med. Science, New Delhi 2003.

[8] Ramakrishnan $\mathrm{U}$, Barnhart $\mathrm{H}$, et al. Nutritional status of school going children. Nutr J 1999; 129(12).

[9] Rockhill B, Moorman PG, Newman B. Age at menarche, time to regular cycling, and breast cancer (North Carolina, United States). Cancer Causes Control 1998; 9(4): 447-53. http://dx.doi.org/10.1023/A:1008832004211

[10] Hamilton AS, Mack TM. Puberty and genetic susceptibility to breast cancer in a case-control study in twins. N Engl J Med 2003; 348(23): 2313-22. http://dx.doi.org/10.1056/NEJMoa021293

[11] Maskarinec G, Zhang $Y$, Takata $Y$, et al. Trends of breast cancer incidence and risk factor prevalence over 25 years. Breast Cancer Res Treat 2006; 98(1): 45-55. http://dx.doi.org/10.1007/s10549-005-9129-0

[12] Frontini MG, Srinivasan SR, Berenson GS. Longitudinal changes in risk variables underlying metabolic syndrome $X$ from childhood to young adulthood in female subjects with a history of early menarche: the Bogalusa Heart Study. Int J Obes Relat Metab Disord 2003; 27(11): 1398-404. http://dx.doi.org/10.1038/sj.ijo.0802422

[13] Kaltiala-Heino R, Kosunen E, Rimpelä M. Pubertal timing, sexual behaviour and self-reported depression in middle adolescence. J Adolesc 2003; 26(5): 531-45. http://dx.doi.org/10.1016/S0140-1971(03)00053-8

[14] Adair LS, Gordon-Larsen P. Maturational timing and overweight prevalence in US adolescent girls. Am J Public Health 2001; 91(4): 642-44.

http://dx.doi.org/10.2105/AJPH.91.4.642

[15] Wattigney WA, Srinivasan SR, Chen W, et al. Secular trend of earlier onset of menarche with increasing obesity in black and white girls: the Bogalusa Heart Study. Ethn Dis 1999; 9(2): 181-89.

[16] Romundstad PR, Vatten LJ, Nilsen TI, et al. Birth size in relation to age at menarche and adolescent body size: implications for breast cancer risk. Int J Cancer 2003; 105(3): 400-403.

http://dx.doi.org/10.1002/ijc.11103

[17] Gluckman PD, Hanson MA. Evolution, development and timing of puberty. Trends Endocrinol Metab 2006; 17(1): 712.

\section{http://dx.doi.org/10.1016/.tem.2005.11.006}

[18] Baker JL, Michaelsen KF, Rasmussen KM, et al. Materna prepregnant body mass index, duration of breastfeeding, and timing of complementary food introduction are associated with infant weight gain. Am J Clin Nutr 2004; 80(6): 1579-88.

[19] Ong KK, Emmett PM, Noble S, et al. Dietary energy intake at the age of 4 months predicts postnatal weight gain and childhood body mass index [electronic article]. ALSPAC Study Team. Pediatrics 2006; 117(3): e503-e508.

\section{http://dx.doi.org/10.1542/peds.2005-1668}

[20] Singhal A, Lanigan J. Breastfeeding, early growth and later obesity. Obes Rev 2007; 8(Suppl 1): 51-54.

http://dx.doi.org/10.1111/j.1467-789X.2007.00318.x

[21] Santos Silva I, De Stavola BL, Mann V, et al. Prenatal factors, childhood growth trajectories and age at menarche. Int J Epidemiol 2002; 31(2): 405-12. http://dx.doi.org/10.1093/ije/31.2.405

[22] Dunger DB, Ahmed ML, Ong KK. Early and late weight gain and the tuning of puberty. Mol Cell Endocrinol 2006; 25: 25455; 140-5.

[23] Schneider AP. Breast feeding among the factors which lowers the risk of ovarian cancer. Adolescent Pedi. And Gynecology McGraw Hill Publishers 1987.

[24] Ginna Wall MN. 2007, available at http:www,111i.org//cbi/ biospec.htm 
[25] Kumud K. Nutrition and Dietetics; Department of food and Nutrition, Institute of Home Economics, Elite Publishers 2005.

[26] Karaolis-Danckert N, Buyken AE, Sonntag A, et al. Birth and early life influences on the timing of puberty onset: results from the DONALD (D Ortmund Nutritional and Anthropometric Longitudinally Designed) Study. Am J Clin Nutr 2009; 90(6): 1559-65.

http://dx.doi.org/10.3945/ajen.2009.28259
[27] Blell M, Pollard TM, Pearce MS. Predictors of age at menarche in the Newcastle Thousand Families Study. J Biosoc Sci 2008; 40(4): 563-75.

http://dx.doi.org/10.1017/S0021932007002696

[28] Al-Sahab B, Adair L. Impact of Breastfeeding Duration on Age at Menarche, American Journal of Epidemiology Advance Access published March 23, 2011. 